\title{
Author Correction: Transferrin receptor 2 controls bone mass and pathological bone formation via BMP and Wnt signaling
}

Martina Rauner (D), Ulrike Baschant, Antonella Roetto, Rosa Maria Pellegrino, Sandra Rother, Juliane Salbach-Hirsch (D), Heike Weidner, Vera Hintze (D), Graeme Campbell, Andreas Petzold, Regis Lemaitre, lan Henry, Teresita Bellido, Igor Theurl, Sandro Altamura, Silvia Colucci, Martina U. Muckenthaler, Georg Schett, Davide S. K. Komla-Ebri, J. H. Duncan Bassett (10, Graham R. Williams $\mathbb{D}^{0}$, Uwe Platzbecker and Lorenz C. Hofbauer

Correction to: Nature Metabolism https://doi.org/10.1038/s42255-018-0005-8, published online 7 January 2019.

In the version of this article initially published, affiliation 14 was incorrect, and Deutsche Forschungsgemeinschaft grants SFB1036 and SFB1118 were missing from the Acknowledgements. The errors have been corrected in the HTML and PDF versions of the article. 